\title{
CORRESPONDENCE
}

\section{Foix-Alajouanine is another differential diagnosis in longitudinal myelitis thought to be a case of multiple sclerosis or neuromyelitis optica}

Spinal Cord Series and Cases (2017) 3, 17058; doi:10.1038/ scsandc.2017.58; published online 31 August 2017

We read with great interest the recent paper by Suthiphosuwan et al. ${ }^{1}$, reporting on a patient with a spinal arteriovenous fistula and false-positive aquaporin-4 lgG test. This patient was misdiagnosed as having neuromyelitis optica spectrum disorder (NMOSD). Encouraged by that report, we are bringing for discussion another case of longitudinal extensive transverse myelitis in a middle-aged man. This patient was initially considered to have NMOSD or primary progressive multiple sclerosis (MS), but in fact he had Foix-Alajouanine syndrome. Presentation of this case report was approved by the Ethics Committee at Universidade Metropolitana de Santos, and the patient signed a consent for our report, provided that his identity remained confidential.

A 52-year-old Caucasian man was referred to our MS Center for investigation of a 2-year history of progressive spastic paraparesis, associated with dysesthesia (D6 level), gait instability and urinary sphincter dysfunction. The patient had previously been treated with pulses of corticosteroids and presented worsening of his signs and symptoms. When a second pulse of methylprednisolone was given 6 months later, which further impaired the patient's gait and leg strength, he was referred to our care. Magnetic resonance imaging at that time revealed longitudinal extensive transverse myelitis from D6 to D12 without paramagnetic enhancement. The presence of flow voids in the posterior epidural space of the dorsal and lumbar segments alerted us to the differential diagnosis of vascular etiology for spinal cord disease. Spinal cord angiography revealed a dural fistula starting at D8 in the left intercostal artery, with slow ascending and descending perimedullary drainage. The images are shown in Figure 1. The patient was treated with spinal cord dural fistula embolization and presented partial recovery from his neurological disability over the following months. This approach has been suggested by others. ${ }^{2}$ Foix-Alajouanine syndrome was initially described in $1926^{3}$ as a condition of acute or subacute neurological deterioration without evidence of hemorrhage in a patient with a spinal arteriovenous malformation. Its signs and symptoms are considered to be the result of progressive spinal cord dysfunction from venous congestion. ${ }^{4}$ If not diagnosed and treated in time, there may be thrombosis and infarcts resulting in necrotic myelopathy. ${ }^{4}$ Pulses of intravenous methylprednisolone can cause immediate and severe worsening of motor and sensory symptoms when administered to patients with spinal arterial - venous malformations. ${ }^{5}$ Therefore, before prescribing pulses of methylprednisolone for longitudinally extensive myelitis, other diagnoses beyond NMOSD must be considered.

\section{COMPETING INTERESTS}

The authors declare no conflict of interest.
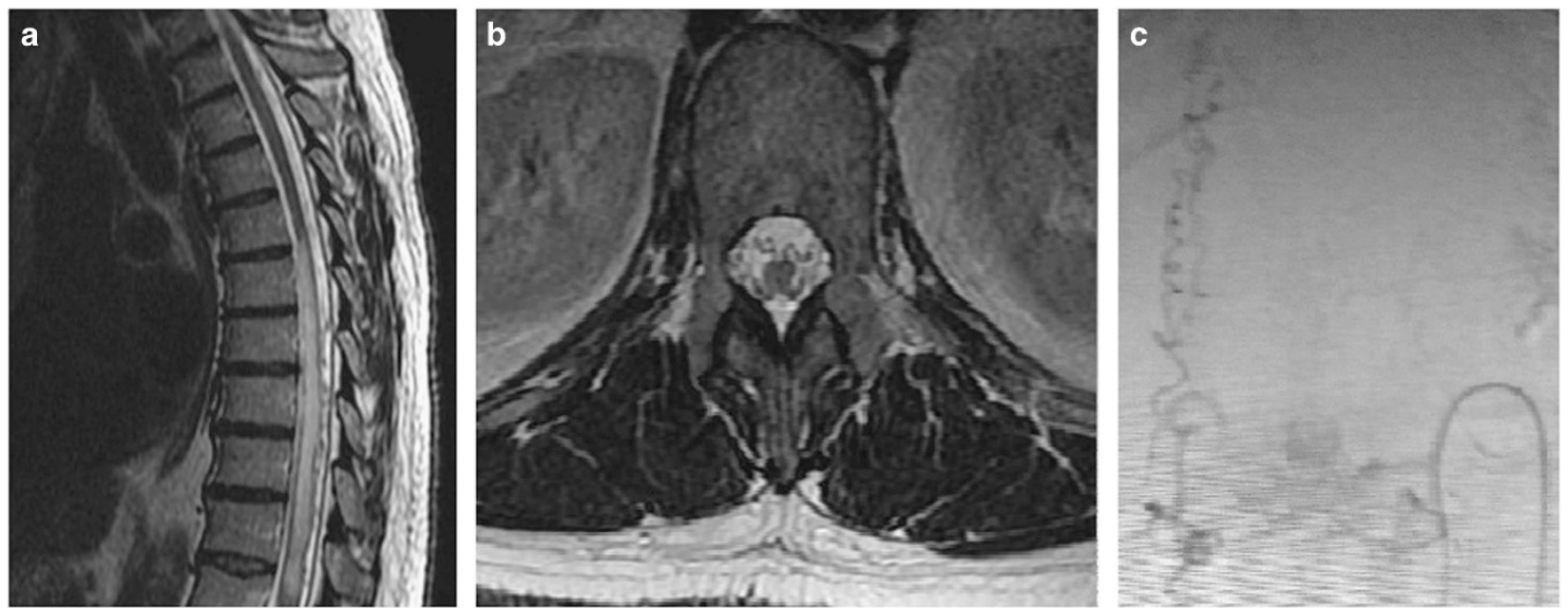

Figure 1. Magnetic resonance imaging revealed longitudinal extensive transverse myelitis from D6 to D12 without paramagnetic enhancement (a). Flow voids in the posterior epidural space of the dorsal and lumbar segments suggested vascular etiology for the spinal cord disease (b). Spinal cord angiography revealed a dural fistula starting at D8 in the left intercostal artery (c). 


\section{PUBLISHER'S NOTE}

Springer Nature remains neutral with regard to jurisdictional claims in published maps and institutional affiliations.

Joseph BB Brooks ${ }^{1}$, Yara D Fragoso ${ }^{2}$, Guilherme N Troiani ${ }^{2}$, Guilherme $L$ da Silveira ${ }^{3}$ and Rodrigo A Oliveira ${ }^{3}$

${ }^{1}$ Department of Structure and Function, Universidade Metropolitana

de Santos, SP, Brazil;

${ }^{2}$ Department of Neurology, Universidade Metropolitana de Santos, $S P$, Brazil and

${ }^{3}$ Megalmagem Radiology, SP, Brazil Correspondence: JBB Brooks (joseph3b@gmail.com)

\section{REFERENCES}

1 Suthiphosuwan S, Oh J, Bharatha A. Clinical pitfall: false-positive aquaporin-4 lgG leading to misdiagnosis of neuromyelitis optica spectrum disorder in patient with spinal arteriovenous fistula. Spinal Cord Ser Cases 2017; 3: 17030.

2 Joswig H, Haji FA, Martinez-Perez R, Steven DA, Boulton MR. Rapid recovery from paraplegia in a patient with Foix-Alajouanine Syndrome. World Neurosurg 2017; 97: 750.e1-750.e3.

3 Foix C, Alajouanine T. La myélite nécrotique subaigue. Rev Neurol (Paris) 1926; 2: 1-42.

4 Criscuolo GR, Oldfield EH, Doppman JL. Reversible acute and subacute myelopathy in patients with dural arteriovenous fistulas: Foix-Alajouanine syndrome reconsidered. J Neurosurg 1989; 70: 354-359.

5 Nasr DM, Brinjikji W, Rabinstein AA, Lanzino G. Clinical outcomes following corticosteroid administration in patients with delayed diagnosis of spinal arteriovenous fistulas. J Neurointerv Surg 2017; 9: 607-610. 